\title{
Reconstrucción de herida grave de miembro superior con colgajo toracoabdominal
}

\author{
Reconstruction of severe upper limb wound \\ with thoracoabdominal flap
}

Sergio Martínez ${ }^{1}$, Natalia Coto Perroni², Paola Carolina Cajide², Griselda Poeta ${ }^{3}$, Rocío Nacir ${ }^{4}$

Palabras clave: antebrazo, codo, heridas complejas, colgajo toracoabdominal, colgajos de cobertura.

Keywords: forearm, elbow, complex wounds, thoracoabdominal flap, cover flaps.

REVISTA ARGENTINA DE CIRUGÍA PLÁSTICA 2018;24(3):140-143. DOI/10.32825/RACP/201803/0140-0143

\section{OBJETIVO}

Evaluar el tratamiento realizado y los resultados obtenidos en la reconstrucción de los miembros superiores con traumatismos severos con pérdidas complejas de los tejidos blandos

\section{INTRODUCCIÓN}

Los defectos de la cobertura de la región del codo y antebrazo son motivo frecuente de consultas para el cirujano plástico y asimismo son un gran desafío; requieren un adecuado planeamiento quirúrgico para su reconstrucción y un equipo multidisciplinario para lograr mejores resultados.

En la superficie anterior de ellos predominan los defectos provocados por quemaduras, térmica o eléctrica, los cuales generan un gran defecto de cobertura que en ocasiones exponen estructuras anatómicas, dejando graves secuelas cicatrizales que limitan la extensión del codo.

En la zona posterior del codo y antebrazo, los defectos más frecuentes son los originados por

1. Jefe del Servicio de Cirugía Plástica y Quemados del Hospital J.C. Perrando. Resistencia, Chaco. Miembro titular SACPERNEA

2. Concurrente del Servicio de Cirugía Plástica y Quemados del Hospital J.C. Perrando. Resistencia, Chaco

3. Concurrente del Servicio de Cirugía Plástica y Quemados del Hospital J.C. Perrando. Resistencia, Chaco

4. Residente del Servicio de Cirugía Plástica y Quemados del Hospital J.C. Perrando. Resistencia, Chaco

$\bowtie$ Correspondencia: Dra. Paola C. Cajide. paocajide@hotmail.com

Los autores no declaran conflictos de intereses traumatismos, quemaduras eléctricas o úlceras por presión.

Cuando pensamos en la reconstrucción de las partes blandas en la región del antebrazo y codo, las opciones son variadas. Las más utilizadas son colgajo chino, colgajo torácico lateral, colgajos DIEP y colgajo dorsal ancho.

En las reconstrucciones de antebrazo y codo debemos aportar tejidos con suficiente elasticidad y resistencia para una rehabilitación funcional precoz, evitar una secuela importante, debe ser un colgajo resistente a una presión directa, debe permitir los movimientos de flexoextensión del codo.

Presentamos en este trabajo un caso de reconstrucción de antebrazo y codo con colgajo dermograso toracoabdominal por ser de fácil acceso, cómodo para el paciente en el posoperatorio (POP) en el ler tiempo y brinda buena cobertura

\section{CASO}

Paciente de 28 años de edad, que ingresa al Servicio de Guardia y Emergencias 14/09/2018 por presentar herida grave avulsiva en miembro superior izquierdo, de 4 hs de evolución posterior a una caída de $3 \mathrm{mts}$ de altura, con lesión de la región del antebrazo con elemento contuso cortante. Al examen físico se observa herida grave avulsiva en cara anterior e interna del codo y antebrazo izquierdo de $20 \times 10 \mathrm{~cm}$ aproximadamente, con sección de músculos flexores superficiales y profundos asociada a lesión del paquete vascular cubital. Se constata extensa contaminación de la herida, bordes desvitalizados, pérdida de la sensibilidad en la región cubital del antebrazo izquierdo e impotencia funcional, exposi- 


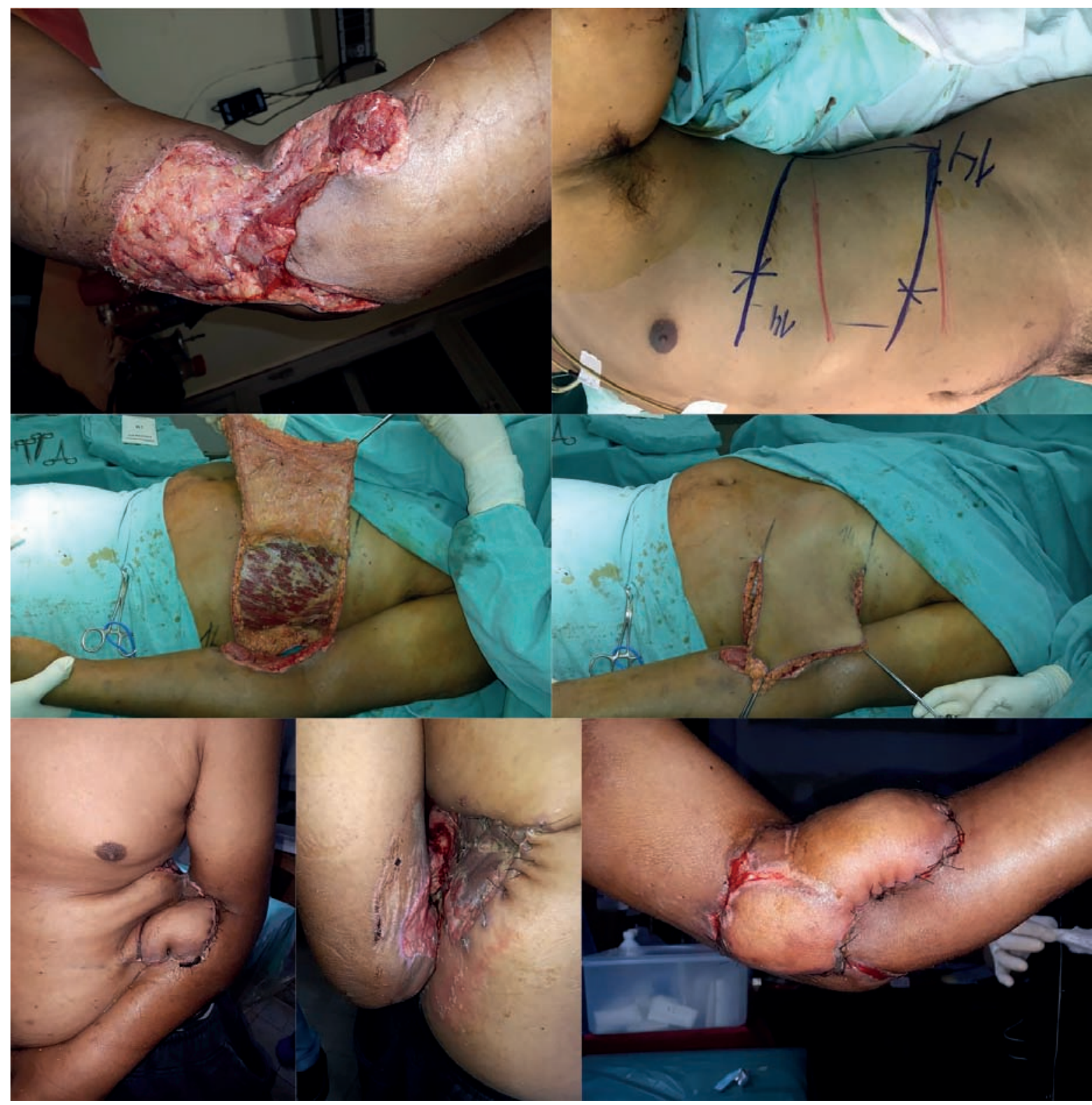

Figura 1.

ción ósea, epitroclear, muscular, tendinosa, con extensa falta de cobertura, compromiso vascular, sangrado activo y signos de flogosis.

Ingresa a quirófano con Servicio de Traumatología y cirugía vascular para toilette quirúrgica y control hemostático del paquete vascular cubital. A los 7 días se evalúa por servicio de Cirugía Plástica, se constata falta extensa de cobertura con exposición muscular y tendinosa, fondo granulante y lecho apto para cierre del defecto. Continúa con la pérdida de sensibilidad en la región cubital de dicho miembro. Se optó por realizar colgajo dermograso toracoabdominal más injerto de piel en tórax por herida grave en antebrazo y brazo izquierdo (1er tiempo quirúrgico). En el POP inmediato se constata colgajo vital, sangrante, con buen relleno y temperatura. Al 4to día POP se da el alta hospitalaria transitoria sin ATB y con controles por consultorio externo.

En el control semanal se interconsulta con Servicio de Infectología debido a la presencia de abundante secreción piocitaria, signos de flogosis y celulitis. Comienza con esquema de ATB de amplio espectro por el término de 10 días.

A los 21 días se realiza sección del colgajo dermograso toracoabdominal. En el ler día POP el paciente evoluciona estable, se constata vitalidad del colgajo, recupera movilidad del miembro superior izquierdo. Continúa con leve parestesia de la zona del cubital. A las 48 hs se indica alta hospitalaria transitoria sin ATB y con controles por consultorio externo. 
En los controles posteriores presenta herida seca, colgajo vital, recupera la funcionalidad del miembro superior izquierdo. Comienza con kinesiología, rehabilitación postural y funcional, lográndose de esta manera su reinserción laboral y pronta recuperación (Figura 1).

\section{DISCUSIÓN}

Cuando planteamos la reconstrucción de partes blandas en un paciente con herida grave en antebrazo y codo, se evalúa un colgajo de fácil realización y buena resolución, devolviendo la funcionalidad de la articulación, con pocos defectos estéticos tanto en la zona dadora como receptora, Debido a la extensa variedad de opciones terapéuticas para la reconstrucción de los miembros superiores, es difícil establecer un algoritmo de tratamiento; cada lesión es única y requiere un tratamiento individualizado. Es necesario un abordaje multidisciplinario. Los resultados son casi siempre satisfactorios cuando se realiza un tratamiento intensivo de las lesiones y la cobertura temprana de los defectos. El objetivo del tratamiento es restaurar la función del miembro afectado. La primera etapa de la reconstrucción comienza por entender la extensión de la lesión y establecer metas realistas en el momento de la primera intervención quirúrgica. Las lesiones graves de los miembros exigen con frecuencia una decisión inmediata o temprana de si el miembro va a ser amputado o se intentará salvarlo. Cuando se decide proceder con la reconstrucción, su realización temprana evita múltiples procedimientos, permite la pronta rehabilitación, disminuye los tiempos de inmovilización, lleva a la curación primaria de la herida, y disminuye los costos y la estadía hospitalaria.

Las variantes terapéuticas para la reconstrucción de heridas de miembros superiores que no pueden ser cubiertos en forma directa con cierre simple, injerto de piel o con la ayuda de VAC, incluyen colgajos rotacionales, pediculados y libres. El tipo de colgajo se elige de acuerdo con consideraciones anatómicas, específicamente, la ubicación de la lesión, el tamaño del defecto y la disponibilidad de tejidos blandos para la cobertura. Cuando hay una lesión ósea grave con- comitante, el tratamiento con un colgajo libre tiene muchas menos posibilidades de ocasionar complicaciones de la herida a corto plazo que si se emplea un colgajo rotacional, aunque no hay recursos para su realización en nuestro hospital motivo por el cual es necesario derivar al paciente a un centro de mayor complejidad.

Los colgajos se indican cuando hay expuesto hueso, tendón, nervio o vasos, ante articulaciones expuestas y en áreas que necesitan movimiento. Los colgajos musculares se prefieren en los defectos profundos, en las exposiciones óseas extensas o de varios días de evolución y en las heridas infectadas. Los colgajos de solo fascia y fasciocutáneos se utilizan para cubrir las estructuras que necesitan deslizarse y cuando existe exposición ósea de corta evolución sin fractura y en heridas sin infección. Los colgajos pediculados randomizados, en este caso el colgajo toracoabdominal, fue una opción adecuada y acertada ya que en nuestra institución no cuenta con la infraestructura necesaria para realizar colgajos libres.

El colgajo toracoabdominal para la reconstrucción del miembro superior es de fácil realización, menor tiempo quirúrgico, de buena evolución y resolución. Diversos autores han postulado que el tiempo de cobertura debe efectuarse dentro de los siete días del traumatismo para disminuir la prevalencia de complicaciones, como osteomielitis y falla de los colgajos.

\section{CONCLUSIONES}

La importancia de la reconstrucción de los miembros superiores con graves lesiones está ampliamente demostrada. El uso del colgajo toracoabdominal para la reconstrucción del miembro superior por la falta extensa de cobertura de los tejidos blandos, es de fácil acceso, y es importante su temprana realización para cerrar las heridas, promover la revascularización del miembro lesionado, prevenir infecciones y complicaciones a futuro, acortar el tiempo de tratamiento, disminuir el edema, el dolor, recuperar la movilidad funcional del miembro afectado y facilitar el cuidado del paciente, así como disminuir los costos de internación en el nosocomio. 


\section{BIBLIOGRAFÍA}

1. Rouviere H. Anatomía humana, descriptiva y topográfica. Tomo III. Ed. Bailly-Bailliere, Madrid. 1980. Pp: 212.230.

2. Mathes SJ, Nahai F. Principles generals. En: Mathes y Nahai. Reconstructive surgery. Principles, Anatomy \& Techniques. Ed. Churchill-Livingstone, 1997. Vol. I.

3. Graciano R, Marin M, Londinsky M. Opciones de cobertura para defectos en codo. Cir Plast Iberolatinoam 2012;38: 363-8.

4. Latifi R, El-Hennawy H, El-Menyar A, Peralta R, Asim M, Consunji $R$ Al-Thani H.: The therapeutic challenges of degloving soft-tissue injuries. J Emerg Trauma Shock. 2014;7(3):228-32.
5. Montaner E, Perez-Correa I, Perez-Blanco A, et al. Colgajo braquial la teral de flujo inverso para cobertura de la región posterior del codo, tras exéresis de sarcoma de partes blandas. Rev Iberoam Cir Mano 2014;42:54-60.

6. Allende BT, Wilson JN. Chirurgie reconstructive du pouce possibilites offertes par l'utilisation de doigts voisins blesses. A propos de 4 observations. Rev Chir Orthop Repar Appar Mot. 1968;54:715-24. 